\title{
The Impact of an All-Female Healthcare Environment on Mentorship and Empowerment of Female Healthcare Professionals in LMICs
}

\section{Naikhoba Munabi ( $\sim$ nmunabi@gmail.com )}

USC Keck School of Medicine: University of Southern California Keck School of Medicine https://orcid.org/0000-0003-2731-837X

\section{Allyn Auslander}

Operation Smile

Meredith D. Xepoleas

Operation Smile

Libby D. Bunker

Operation Smile

Kella L. Vangsness

Children's Hospital of Los Angeles

\section{Sara Koualla}

Faculte de Medecine et de Pharmacie d'Oujda

Kathy S. Magee

Operation Smile

William P. Magee

Children's Hospital of Los Angeles

Caroline A. Yao

Shriners Hospitals for Children Pasadena

\section{Research}

Keywords: Health Workforce, Mentorship, Women, Leadership

Posted Date: December 16th, 2020

DOl: https://doi.org/10.21203/rs.3.rs-127292/v1

License: (c) (1) This work is licensed under a Creative Commons Attribution 4.0 International License.

Read Full License 


\section{Abstract}

Background: Low- and middle-income countries (LMICs) have the greatest need for additional healthcare providers, and women outside the workforce could help address the need. Women in healthcare need more mentorship and leadership training to advance their careers. This study evaluates how women working together on a medical team impacts mentorship, leadership and empowerment.

Methods: An all-female volunteer team participating in a cleft surgery mission in Oujda, Morocco were surveyed before and after the mission. Responses were analyzed according to country of origin, national gender equality ranking, volunteer role, and prior mentorship experiences. Statistical analysis with student's t-test or chi-squared were performed with significance defined as $p<0.05$.

Results: 95 female volunteers from 23 countries participated and $85 \%$ completed surveys. Volunteers from HICs (32\%) and LMICs (68\%) had similar mission roles $(\mathrm{p}=0.58)$ and duration of volunteerism $(p=0.69)$. Experience as a mission volunteer $(p=0.47)$, team leader $(p=0.28)$, and educator $(p=0.18)$ were equivalent between cohorts. $73 \%$ of women had previously received mentorship but $98 \%$ wanted more. $75 \%$ had previously mentored others, but $97 \%$ wanted to be mentors. Over $90 \%$ of past mentor-mentee relationships were between women. $73 \%$ of volunteers who had no prior mentorship found their first mentor during the mission. All participants found a long-term peer relationship and felt motivated to mentor women at home. All volunteers felt empowered and enjoyed the mission. Over $95 \%$ were inspired to pursue leadership positions, advance professionally, and work with other women at home.

Conclusion: Female healthcare professionals in HICs and LMICs desire more mentorship than is available. An all-female healthcare environment can provide opportunities for mentorship and create lasting motivation to teach, lead, and advance professionally. Increasing the visibility of female professionals may effectively empower women in healthcare.

\section{Introduction}

Eighteen million more healthcare workers, most prominently in low- and middle-income countries (LMICs), are needed globally to provide safe and accessible surgical care to the world's population [1]. Over one billion women worldwide, the majority of whom live in LMICs, do not participate in the traditional workforce. Women are therefore the largest demographic of people that can be mobilized into healthcare to fill current gaps [2].

Increasing the number of women in healthcare requires understanding barriers to entrance and advancement. While $70 \%$ of healthcare roles are currently filled by women, the majority of leadership positions are held by men. Seventy-five percent of senior roles in medicine are held by men, $69 \%$ of global health organizations are led by men, and $80 \%$ of healthcare boards are exclusively men $[3,4]$. Studies suggest that lack of female representation in leadership positions, restrictive cultural gender norms, and lack of mentorship contribute to limited engagement and advancement of women in medicine [5-9]. 
Few studies have examined women in healthcare in LMICs, and $90 \%$ of studies on gender in surgery are from high income countries (HICs) [10]. Knowledge of baseline working conditions for women in medicine are needed to create effective initiatives. Without engaging women in LMICs, gender equity in medicine is estimated to take over 200 years [4].

Operation Smile, a global nonprofit with 6000 volunteers from over 60 countries, runs hundreds of surgical programs each year in LMICs. In the last five years, over $60 \%$ of active volunteers were women from around the world. To celebrate the contributions of women to the organization and healthcare worldwide, Operation Smile held a cleft mission with an all-female volunteer team in Oujda, Morocco on International Women's Day 2020. With 95 female healthcare workers from 23 countries, this environment was an opportunity for women to work, learn, and establish professional relationships. This study evaluates the programmatic impact on participant experiences, mentorship, and career aspirations. We focused on whether interaction with female peers could promote mentorship, leadership development, and empowerment for women in medicine globally.

\section{Methods}

An anonymous survey was administered during an Operation Smile cleft surgery mission in Oujda, Morocco (March 2020) with all-female team. The following providers were surveyed: doctors (surgeons, anesthesiologists, pediatricians), nurses (operating room, intensive care/PACU, ward nurses), other medical volunteers (speech pathologists, dentists, child-life specialists, medical records specialists, biomedical engineers, patient imaging technicians), and nonmedical volunteers (administrators, program coordinators, translators, students). Each specialty had a team leader responsible for assignment of tasks, upholding standards of care, and multidisciplinary team communication. Volunteers present for the entire mission were eligible for participation. Ethics approval for this study was obtained from Children's Hospital Los Angeles (IRB \#CHLA 20-00026) and Operation Smile, Inc. (Virginia Beach, VA).

Surveys were administered pre-mission (baseline) and post-mission to evaluate attitude changes. Questions focused on volunteer demographics, prior exposure to female professionals, and experience with mentorship and leadership. Opinion questions used a 4-point Likert scale.

Pre- and post-mission survey responses were analyzed independently and as paired data. Responses were analyzed according to age, country of origin (geographic region and World Bank income level grouping) [11], country gender equity ranking (World Economic Forum Global Gender Gap Index) [12], mission role, and prior mentorship experiences. Data were recorded in RedCap (Vanderbilt University, Nashville, TN) and analyzed using student's t-test or chi-squared. Analyses were performed in Excel (Microsoft Corp, Redmond, WA) and R (R Core Team, Vienna, Austria). Significance was defined as $p<$ 0.05 .

\section{Results}




\section{Descriptive Statistics}

Ninety-five women participated in the mission and all were eligible for the study. Seventy (74\%) were medical volunteers (physicians, nurses, and other medical professionals) and twenty-five (26\%) were nonmedical volunteers (administrators, translators, or students). Volunteers came from 23 different countries and $68 \%(n=65)$ were from LMICs (Fig. 1).

Pre-mission, post-mission, and both surveys were completed by $85 \%(n=81), 81 \%(n=77)$, and $74 \%(n=$ 70) of volunteers, respectively. Volunteers had an average of $8.1 \pm 7.3$ years' experience working with Operation Smile. The majority of participants had been on 11-15 prior missions with the organization. Twenty-nine percent of volunteers had prior experience as a team leader and $28 \%$ as an educator for Operation Smile. Volunteers from HICs and LMICs had similar mission roles $(p=0.58)$, number of prior missions $(p=0.47)$, duration of volunteerism $(p=0.69)$, team leader experience $(p=0.28)$ and educator experience $(p=0.18)$ (Table 1$)$.

Table 1

Demographics of Survey Respondents from high income countries (HIC) and lower- and middle-income countries (LMICs)

\begin{tabular}{|c|c|c|c|c|}
\hline & $\begin{array}{c}\mathrm{HIC} \\
(\mathrm{n}=22)\end{array}$ & $\begin{array}{l}\text { LMIC } \\
(n=56)\end{array}$ & $\begin{array}{l}\text { Overall } \\
(\mathrm{N}=81)\end{array}$ & P-value \\
\hline \multicolumn{5}{|l|}{ Region } \\
\hline East Asia and Pacific & $2(9.1 \%)$ & $1(1.8 \%)$ & $3(3.7 \%)$ & \\
\hline Europe and Central Asia & $7(31.8 \%)$ & $1(1.8 \%)$ & $8(9.9 \%)$ & \\
\hline Latin America \& the Caribbean & $1(4.5 \%)$ & $11(19.6 \%)$ & $12(14.8 \%)$ & \\
\hline Middle East and North Africa & $0(0 \%)$ & $30(53.6 \%)$ & $31(38.3 \%)$ & \\
\hline North Americe & $12(54.5 \%)$ & $3(5.4 \%)$ & $17(21.0 \%)$ & \\
\hline Sub-Saharan Africa & $0(0 \%)$ & $10(17.9 \%)$ & $10(12.3 \%)$ & \\
\hline \multicolumn{5}{|l|}{ Age, years } \\
\hline Mean (SD) & $41.1(15.1)$ & $40.0(14.4)$ & $40.5(14.7)$ & \multirow{2}{*}{0.77} \\
\hline Median [Min, Max] & $41.5[17.0,65.0]$ & $36.0[20.0,73.0]$ & $39.0[17.0,73.0]$ & \\
\hline \multicolumn{5}{|l|}{ Role on the Mission $t$} \\
\hline Doctor & $6(27.3 \%)$ & $17(30.4 \%)$ & $23(28.4 \%)$ & \multirow{4}{*}{0.58} \\
\hline Nonmedical & $8(36.4 \%)$ & $12(21.4 \%)$ & $20(24.7 \%)$ & \\
\hline Nurse & $4(18.2 \%)$ & $15(26.8 \%)$ & $21(25.9 \%)$ & \\
\hline Other Medical & $4(18.2 \%)$ & $12(21.4 \%)$ & $17(21.0 \%)$ & \\
\hline \multicolumn{5}{|c|}{ Number of Missions Previous ly Attended } \\
\hline 4 or fewer & $9(40.9 \%)$ & $16(28.6 \%)$ & $25(30.9 \%)$ & \multirow{6}{*}{0.47} \\
\hline $5-10$ & $5(22.7 \%)$ & $10(17.9 \%)$ & $15(18.5 \%)$ & \\
\hline $10-15$ & $4(18.2 \%)$ & $8(14.3 \%)$ & $14(17.3 \%)$ & \\
\hline $16-20$ & $0(0 \%)$ & $5(8.9 \%)$ & $5(6.2 \%)$ & \\
\hline $21-25$ & $0(0 \%)$ & $3(5.4 \%)$ & $3(3.7 \%)$ & \\
\hline 26 or more & $4(18.2 \%)$ & $14(25.0 \%)$ & $19(23.5 \%)$ & \\
\hline \multicolumn{5}{|c|}{ Duration of Volunteer Engagement, years } \\
\hline Mean (SD) & $7.7(7.3)$ & $8.2(7.4)$ & $8.1(7.3)$ & \multirow{2}{*}{0.69} \\
\hline Median [Min, Max] & $5[0,27]$ & $6[0,25]$ & $5[0,27]$ & \\
\hline \multicolumn{5}{|l|}{ Prior Operation Smile Roles } \\
\hline Team Leader & $4(18.2 \%)$ & $19(33.9 \%)$ & $24(29.6 \%)$ & 0.18 \\
\hline Educator & $8(36.4 \%)$ & $14(25.0 \%)$ & $23(28.4 \%)$ & 0.28 \\
\hline
\end{tabular}


† Doctor includes anesthesiologists, cleft surgeons, PACU physicians, pediatricians; Nonmedical includes administrators, translators, and students; Nurses includes clinical coordinators, operating room, PACU and ward nurses; Other medical includes dentists, speech language pathologists, child life specialists, medical records, biomedical engineer, and photography technicians.

\section{Female representation in home environments}

In their home countries, nurses tended to work in female dominated workplaces whereas physicians tended to work in male-dominated environments (Fig. 2). Volunteers from Europe and Latin America worked with more women professionally versus sub-Saharan Africa, the Middle East and North Africa, and North America. Only 3 volunteers originated from East Asia and the Pacific (Fig. 3A). Volunteers from LMICs and HICs had similar estimates for prevalence of female healthcare workers at home $(p=0.66)$ (Fig. 3B).

\section{Mentorship}

Most women had mentored or received mentorship from other woman before (Table 2). 73\% $(n=59)$ had previously received mentorship from a colleague, most of whom were women $(90 \%, n=53)$. Similarly, $75 \%$ of women $(n=61)$ had previously mentored a colleague; most of their mentees were female $(93 \%, n$ = 57). Nearly all volunteers wanted to be mentors for others, especially for women ( $97 \%$ and $97 \%$, respectively). (Fig. 4) However, women from both HICs and LMICs struggle to get enough mentorship. $98 \%$ of volunteers $(n=79)$ felt their mentorship was insufficient and $95 \%(n=77)$ preferred a female mentor. Volunteer role (doctor, nurse, other medical, non-medical) was not associated with receiving $(p=$ $0.129)$ or giving $(p=0.118)$ mentorship.

Table 2

Prior experience with female mentorship

\begin{tabular}{|c|c|c|c|c|}
\hline & $\begin{array}{l}\text { HIC } \\
(n=22)\end{array}$ & $\begin{array}{l}\text { LMIC } \\
(n=56)\end{array}$ & $\begin{array}{l}\text { Overall } \\
(\mathrm{N}= \\
81)\end{array}$ & $\begin{array}{l}\mathrm{P} \text { - } \\
\text { value }\end{array}$ \\
\hline $\begin{array}{l}\text { Had experience working in an all-female professional } \\
\text { environment }\end{array}$ & $\begin{array}{l}8 \\
(36 \%)\end{array}$ & $\begin{array}{l}18 \\
(32 \%)\end{array}$ & $\begin{array}{l}26 \\
(32 \%)\end{array}$ & 0.91 \\
\hline Received mentorship from a colleague & $\begin{array}{l}17 \\
(77 \%)\end{array}$ & $\begin{array}{l}39 \\
(70 \%)\end{array}$ & $\begin{array}{l}59 \\
(73 \%)\end{array}$ & 0.97 \\
\hline Received mentorship from a female colleague & $\begin{array}{l}16 \\
(73 \%)\end{array}$ & $\begin{array}{l}34 \\
(61 \%)\end{array}$ & $\begin{array}{l}53 \\
(65 \%)\end{array}$ & 0.73 \\
\hline Mentored a colleague & $\begin{array}{l}17 \\
(77 \%)\end{array}$ & $\begin{array}{l}41 \\
(73 \%)\end{array}$ & $\begin{array}{l}61 \\
(75 \%)\end{array}$ & 0.64 \\
\hline Mentored a female colleague & $\begin{array}{l}15 \\
(68 \%)\end{array}$ & $\begin{array}{l}39 \\
(70 \%)\end{array}$ & $\begin{array}{l}57 \\
(70 \%)\end{array}$ & 0.90 \\
\hline
\end{tabular}

Living in a HIC versus LMIC did not influence prior experience receiving mentorship (77\% vs $70 \%, p=0.97)$ or being mentored by a woman ( $73 \%$ vs $61 \%, p=0.73)$. Similarly, giving mentorship to a colleague $(77 \%$ 
vs $73 \%, p=0.64)$ or female colleague $(68 \%$ vs $70 \%, p=0.90)$ was equivalent in HICs and LMICs.

At this mission, many women gave and received mentorship for the first time. $68 \%(n=52)$ mentored others; $42 \%$ ( $n=5$ of 12 ) who had never mentored before became mentors for the first time. $77 \%(n=59)$ of volunteers received mentorship. 15 participants had never been mentored before, and 11 of them (73\%) received mentorship for the first time. Mentorship during the mission had a trickle-down effect for participant home countries. $100 \%$ established professional contacts to maintain in the future and $100 \%$ felt empowered to mentor working women at home (Fig. 5).

\section{Experience in prior all-female environments}

Twenty-six women (32\%) had prior experience working in an all-female professional environment. Prior work in an all-female environment was not associated the with volunteer's profession $(p=0.807)$, selfreported gender equity at home $(p=0.529)$, or prior mentorship experience (giving $p=0.930$; receiving $p=$ 1.00).

\section{Leadership development}

Participants anticipated being empowered by the all-female mission experience with $98 \%$ expecting empowerment before and $99 \%$ reporting empowerment afterwards $(p=0.196)$. Volunteers did not expect to enjoy the mission as much as they did, with $75 \%$ expecting to enjoy the experience before versus $87 \%$ reporting they enjoyed the experience after $(p=0.040)$.

Only $16 \%(n=12)$ of participants were team leaders. Nevertheless $99 \%(n=76)$ felt inspired to pursue leadership positions in their home countries and 93\% $(n=72)$ within Operation Smile. $99 \%(n=76)$ of participants felt motivated to advance professionally in their career and $97 \%(n=75)$ wanted to work with other women in their career.

\section{Discussion}

Overall, participating in an all-female work environment was enjoyable, empowering, and career motivating. The volunteers from HICs and LMICs reported equivalent gender inequality in their home countries. Fewer women were working as doctors versus nurses. These data are consistent with the literature that reports the majority of healthcare workers are women, but fewer hold higher skilled jobs [13].

\section{Gender inequity in medicine in not related to economic standing of a country}

According to the World Economic Forum's Global Gender Gap Index (GGGI), women have less equality in the Middle East and North Africa (MENA), sub-Saharan Africa, and Asia [12]. Our volunteers estimated the prevalence of women in healthcare in their home countries; their estimates suggest counties with lower gender equity rankings had fewer women than men working in professional environments. Volunteers 
from Europe and Latin America reported greater presence of female professionals, consistent with the regions' high gender equity rankings. In contrast, North America has a high gender equity rating, but volunteers report fewer women working in healthcare. This discrepancy between North America versus Europe and Latin American may relate to more social services and family support in the latter two regions [14].

\section{Mentorship is universally difficulty to achieve for women in medicine}

Prior to this mission, $25 \%$ of women had not gotten the mentorship they wanted in their home countries, regardless of profession and region. This suggests that lack of mentorship is a struggle for women as a whole rather than a specific cultural, economic, or career phenomenon.

An all-female mission provided a safe space to teach and be taught. Both of these experiences are essential, as mentoring is a learned skill. Studies suggest that mentoring capabilities evolve over time and can lead to professional development of both the mentor and mentee [15]. Women who were not designated team leaders on the mission still engaged in mentoring roles. The overall supportive environment may have inspired peer teaching and engagement.

The impact of the all-female environment extended beyond the mission. Participants established professional contacts they intended to maintain, allowing for continued mentorship and career development. Individuals were inspired to pursue mentorship when returning home. A 2017 study in the United States of America (U.S.) found that access to a mentor-mentee relationship, especially at earlier stages of a career, can lead to more retention and sustainability of women in STEM fields [16]. The literature and present study showcase how women can educate other women with lasting impact.

\section{An all-female professional environment helped to develop female leaders}

In volunteer home countries, pursuing leadership positions can be challenging for women. In a study of female oncologists in the Middle East, mothers were discouraged from pursuing leadership, even though they felt capable [17]. In an expanded study of female healthcare workers in the U.S., Haiti, Tanzania, and India, 53\% reported that gender discrimination prevented promotions [18].

Despite challenging environments, the all-women mission inspired participants to pursue leadership positions at home. Studies reporting public support of gender equity in the workplace helps women advance professionally [18]. Many were empowered by the mission and were pleasantly surprised by how much they enjoyed the experience. These data show that women find it meaningful and enjoyable working together [19]. Women in leadership roles also decreases gender discrimination in maledominated fields [20]. These collective sentiments help explain why almost all participants wanted to continue working with other women and advance in a leadership role at home. Geographic region or country economic status did not affect this desire, suggesting a universal impact of the experience. 


\section{Limitations}

Philanthropic environments are not comparable to normal professional environments. Those who volunteer likely have stronger desires to educate, learn and grow. Additionally, women who had the opportunity to leave their normal responsibilities for a 10-day mission likely had strong work and familial support; these volunteers may not represent the average woman in their country. Secondly, the small number of participants from each country and region limits our ability to draw generalizable conclusions about individual countries. Lastly, longitudinal follow up of this cohort is needed to confirm long-term impact of the mission experience. In the future, we plan to study control groups: women who did not participate in a mission, or women who participated in a mixed-gender mission. This future study aims to separate the effects of an all-female workplace from general philanthropic participation.

\section{Conclusion}

Initiatives that bring professional women into an all-female work environment can have lasting impact on their lives and careers through encouraging leadership and pairing of mentors with mentees. Increasing interactions between women in healthcare can lead to advancement in both HICs and LMICs. Without purposeful initiatives to increase female participation in healthcare, gender equity in medicine will not occur for 200 years [5]. More healthcare providers are needed now; if governments and healthcare systems promote women in medicine, the needs of the global population can be met faster.

\section{Abbreviations}

U.S.

United States of America

HIC

High Income Country

LMIC

Low- and- Middle- Income- Country

\section{Declarations}

Ethics approval and consent to participate: Ethics approval for this study was obtained from Children's Hospital Los Angeles (IRB \#CHLA 20-00026) and Operation Smile, Inc. (Virginia Beach, VA).

Consent for Publication: Not applicable.

Availability of data and materials: All data generated or analyzed during this study are included in this published article.

Competing interests: The authors declare that they have no competing interests.

Funding: No funding was used. 
Authors' contributions: N.M., A.A, L.B., K.M, W.M., and C.Y. contributed to study design and questionnaire development. N.M., K.V., and S.K. performed questionnaire distribution and collection. N.M. and A.A. completed statistical analysis. N.M, A.A., L.B., K.V., S.K., and C.Y. participated in interpretation of results. N.M., M.X, and C.Y. drafted the manuscript. All authors read and approved of the final manuscript.

Acknowledgements: No acknowledgments

\section{References}

1. Meara JG, et al. Global Surgery 2030: evidence and solutions for achieving health, welfare, and economic development. The Lancet. 2015;386(9993):569-624.

2. Aguirre D, et al. Empowering the Third Billion: Women and the world of work in 2012. Booz \& Company 2012. Accessed 19 Jan 2020. Available from:

https://www.strategyand.pwc.com/gx/en/reports/strategyand-empowering-the-third-billion-fullreport.pdf.

3. World Health Organization. "Delivered by women, led by men: A gender and equity analysis of the global health and social workforce." Human Resources for Health Observer 2019; Issue 24: Available from https://apps.who.int/iris/bitstream/handle/10665/311322/9789241515467-eng.pdf?ua=1 .

4. World Health Organization. "10 key issues in ensuring gender equity in the global health workforce". 20 March 2019. Accessed 19 Jan 2020. Available from: https://www.who.int/news-room/featurestories/detail/10-key-issues-in-ensuring-gender-equity-in-the-global-health-workforce.

5. Boylan J, Dacre J. Addressing Women's Underrepresentation in Medical Leadership. The Lancet. 2019;393:e14.

6. Neumayer L, Kaiser S, Anderson K, et al. Perceptions of women medical students and their influence on career choice. Am J Surg. 2002;183(2):146-50.

7. Yorozuya K, Kawase K, Akashi-Tanaka S, Kanbayashi C, Nomura S, Tomizawa Y. Mentorship as Experienced by Women Surgeons in Japan. World J Surg. 2016;40(1):38-44.

8. Umoetok F, Van Wyk JM, Madiba TE. Does gender impact on female doctors' experiences in the training and practice of surgery? A single centre study. S Afr J Surg. 2017;55(3):8-12.

9. Yi S, Lin Y, Kansayisa G, Costas-Chavarri A. A qualitative study on perceptions of surgical careers in Rwanda: A gender-based approach. PLoS One. 2018;13(5):e0197290.

10. Xepoleas M, Munabi NCO, Auslander A, Magee WPIII, Yao CA. Suturing the Inequality Gap: A Scoping Review of Female Surgeon's Experiences Globally. Human Resources for Health 2020; submitted.

11. The World Bank. World Bank Country and Lending Groups. Available at:

https://datahelpdesk.worldbank.org/knowledgebase/articles/906519-world-bank-country-andlending-groups. Accessed 20 March 2020.

12. The World Economic Forum. Global Gender Gap Report 2020. Geneva: The World Economic Forum; 2019. Available at: http://www3.weforum.org/docs/WEF_GGGR_2020.pdf. Accessed 20 March 2020. 
13. The Organisation for Economic Co-operation and Development (OECD). "Gender Equality: Women make up most of the health sector workers but they are under-represented in high-skilled jobs". March 2017. Accessed 13 April 2020. Available from: https://www.oecd.org/gender/data/womenmake-up-most-of-the-health-sector-workers-but-they-are-under-represented-in-high-skilled-jobs.htm.

14. Hughes N, Munoz-Guzman C, Eds. Understanding and Supporting 'Families with Complex Needs'. Basel, Switzerland, MDPI, 2016.

15. Cooke KJ, Patt DA, Prabhu RS. The Road of Mentorship. Am Soc Clin Oncol Educ Book. 2017;37:788-92.

16. Dennehy TC, Dasgupta N. Female peer mentors early in college increase women's positive academic experiences and retention in engineering. PNAS. 2017;114(23):5964-9.

17. Salem R, Haibe Y, Dagher C, et al. Female oncologists in the Middle East and North Africa: progress towards gender equality. ESMO Open. 2019;4:e000487.

18. Mathad JS, Reif LK, Seo G, et al. Female global health leadership: data-driven approaches to close the gender gap. The Lancet. 2019;393(101):521-3.

19. Qian Y, Fan W. Men and Women at Work: Occupational Gender Composition and Affective Well-Being in the United States. J Happiness Stud. 2019;20:2077-99.

20. Eyigor H, Can IH, Incesulu A, Senol Y. Women in Otolaryngology in Turkey: Insight of Gender Equality, Career Development and Work-Life Balance. Am J Otolaryngol. 2020;41(1):102305.

\section{Figures}

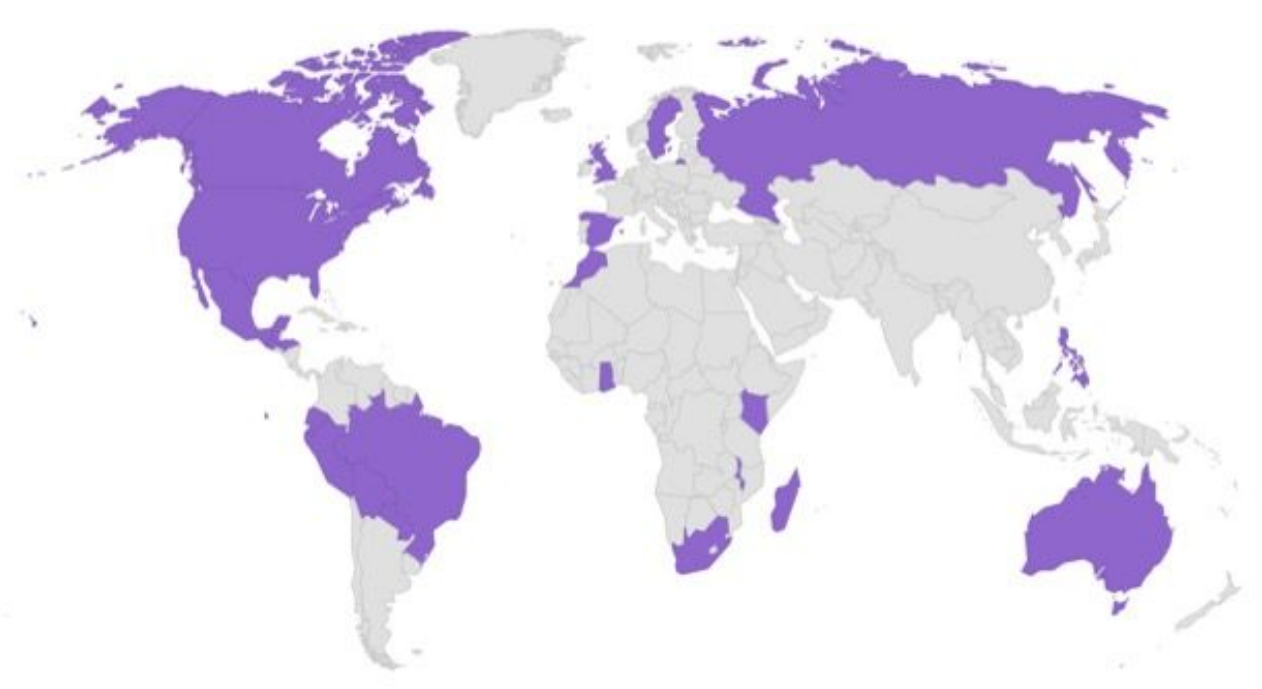

\begin{tabular}{|c|c|}
\hline Australia & 2 \\
\hline Boliva & 1 \\
\hline Brazil & 1 \\
\hline Canada & 4 \\
\hline Ecuador & 2 \\
\hline Egypt & 1 \\
\hline Ghana & 3 \\
\hline Guatemala & 2 \\
\hline Honduras & 1 \\
\hline Kenya & 4 \\
\hline Madagascar & 1 \\
\hline Malawi & 1 \\
\hline Mexico & 2 \\
\hline Morocco & 43 \\
\hline Paraguay & 2 \\
\hline Peru & 2 \\
\hline Philippines & 1 \\
\hline Russia & 1 \\
\hline South Africa & 1 \\
\hline Spain & 3 \\
\hline Sweden & 3 \\
\hline United Kingdom & 2 \\
\hline United States & 12 \\
\hline
\end{tabular}


Figure 1

Home countries of volunteers who participated in the Oujda, Morocco mission Note: The designations employed and the presentation of the material on this map do not imply the expression of any opinion whatsoever on the part of Research Square concerning the legal status of any country, territory, city or area or of its authorities, or concerning the delimitation of its frontiers or boundaries. This map has been provided by the authors.

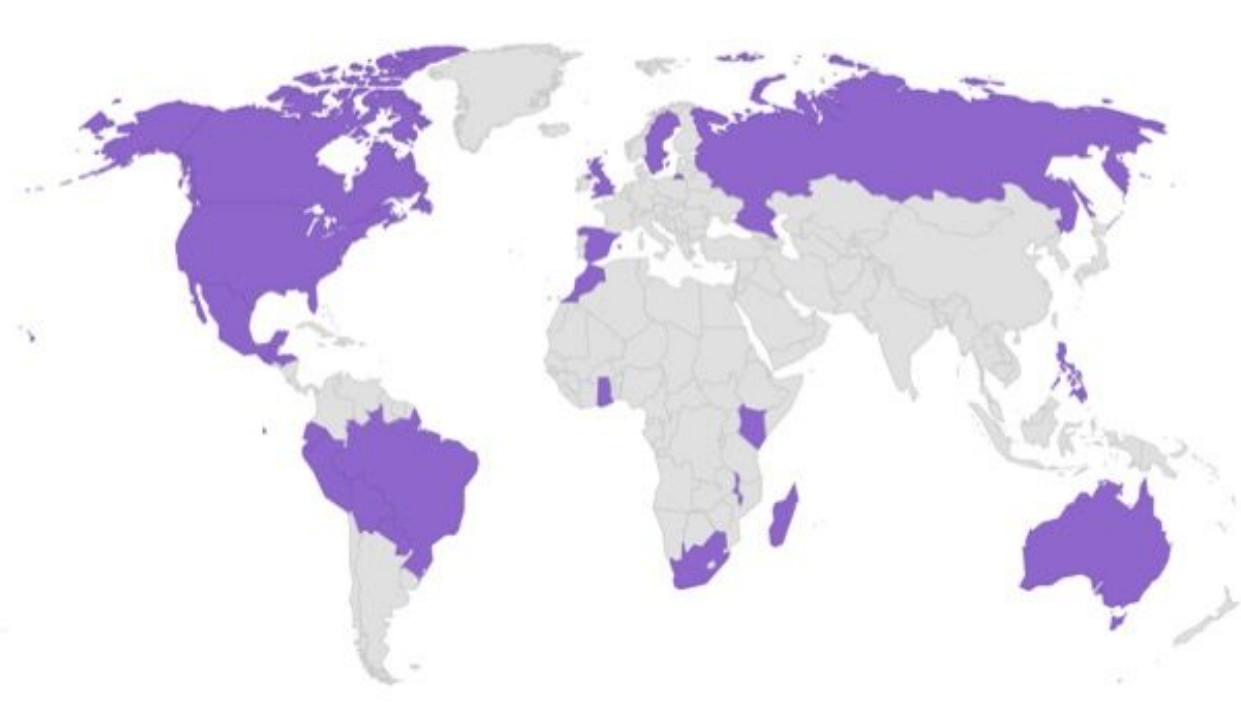

\begin{tabular}{|c|c|}
\hline Australia & 2 \\
\hline Boliva & 1 \\
Brazil & 1 \\
Canada & 4 \\
Ecuador & 2 \\
Egypt & 1 \\
Ghana & 3 \\
Guatemala & 2 \\
Honduras & 1 \\
Kenya & 4 \\
\hline Madagascar & 1 \\
\hline Malawi & 1 \\
\hline Mexico & 2 \\
Morocco & 43 \\
Paraguay & 2 \\
Peru & 2 \\
\hline Philippines & 1 \\
Russia & 1 \\
\hline South Africa & 1 \\
Spain & 3 \\
Sweden & 3 \\
United Kingdom & 2 \\
United States & 12 \\
\hline
\end{tabular}

\section{Figure 1}

Home countries of volunteers who participated in the Oujda, Morocco mission Note: The designations employed and the presentation of the material on this map do not imply the expression of any opinion whatsoever on the part of Research Square concerning the legal status of any country, territory, city or area or of its authorities, or concerning the delimitation of its frontiers or boundaries. This map has been provided by the authors. 
80

70

× 60

这 50

40

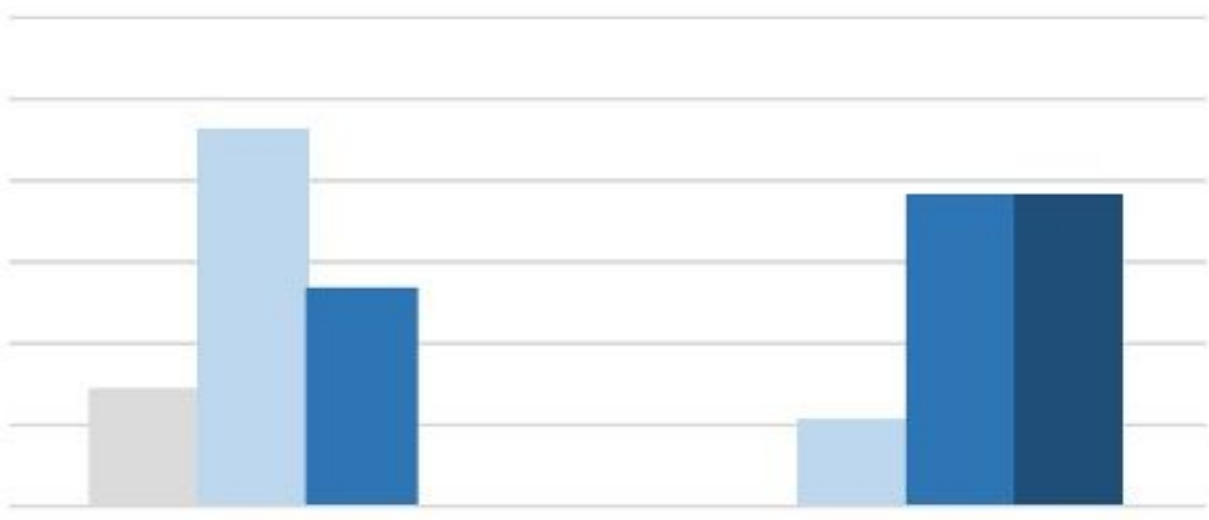

$<25 \%$

$=26-50 \%$

— $51-75 \%$

- $76-100 \%$

Doctor

Nurse

\section{Figure 2}

In your home country, what percentage of doctors or nurses are women? Volunteer estimates (overall):

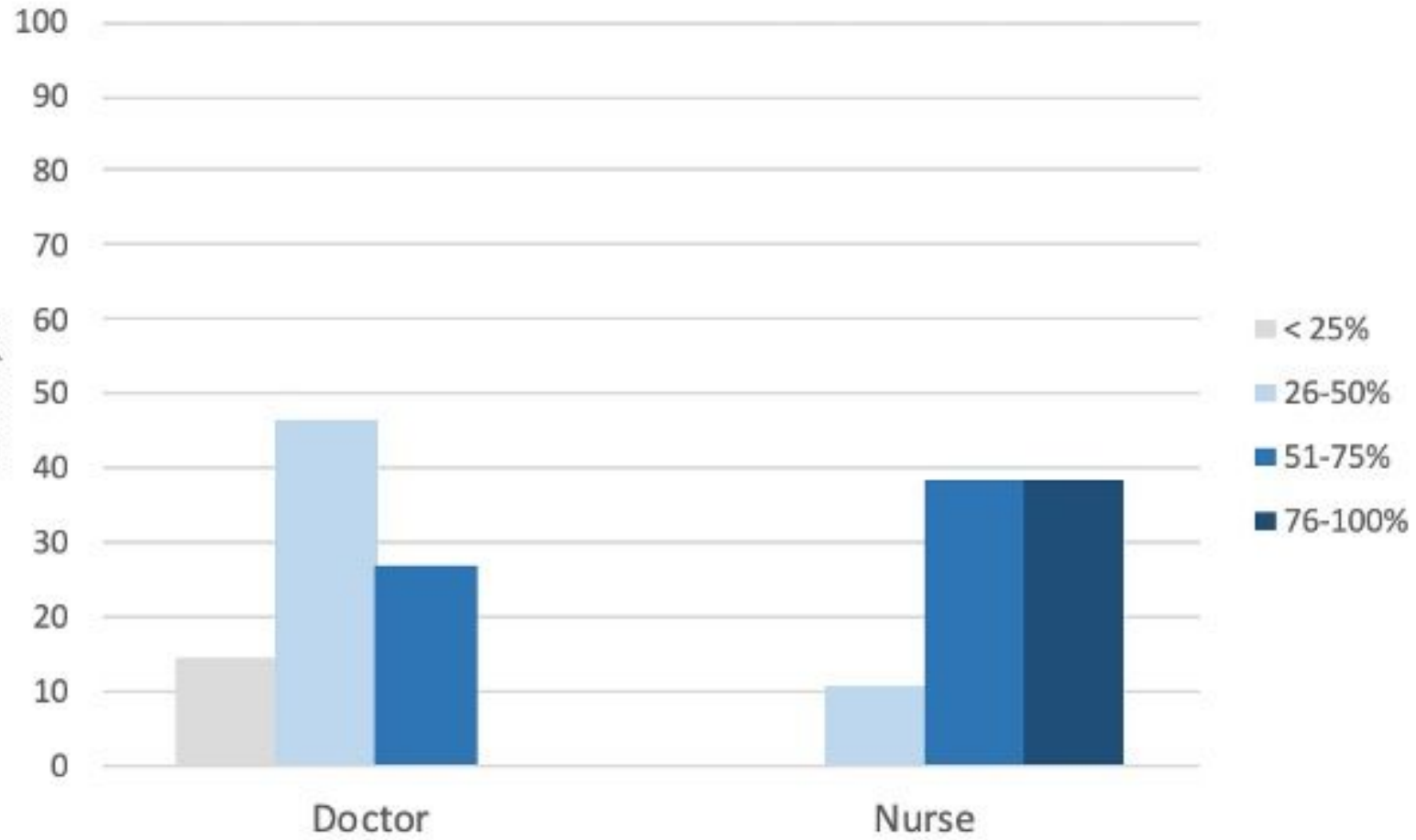

Figure 2

In your home country, what percentage of doctors or nurses are women? Volunteer estimates (overall): 

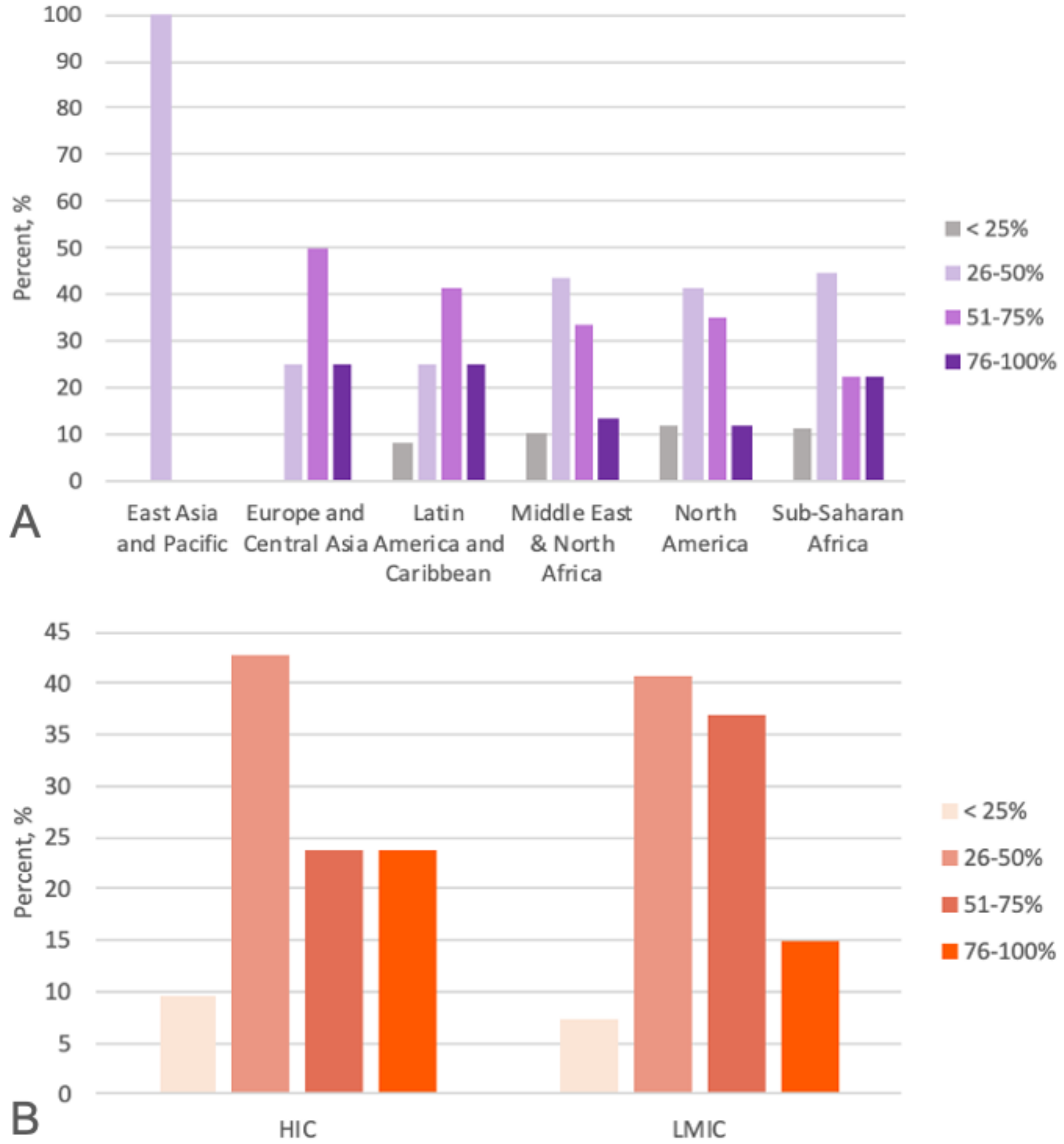

\section{Figure 3}

In your home country, what percentage of medical professionals are women? A. By Volunteer Home Region: B. By Volunteer Home Country Income Level: 

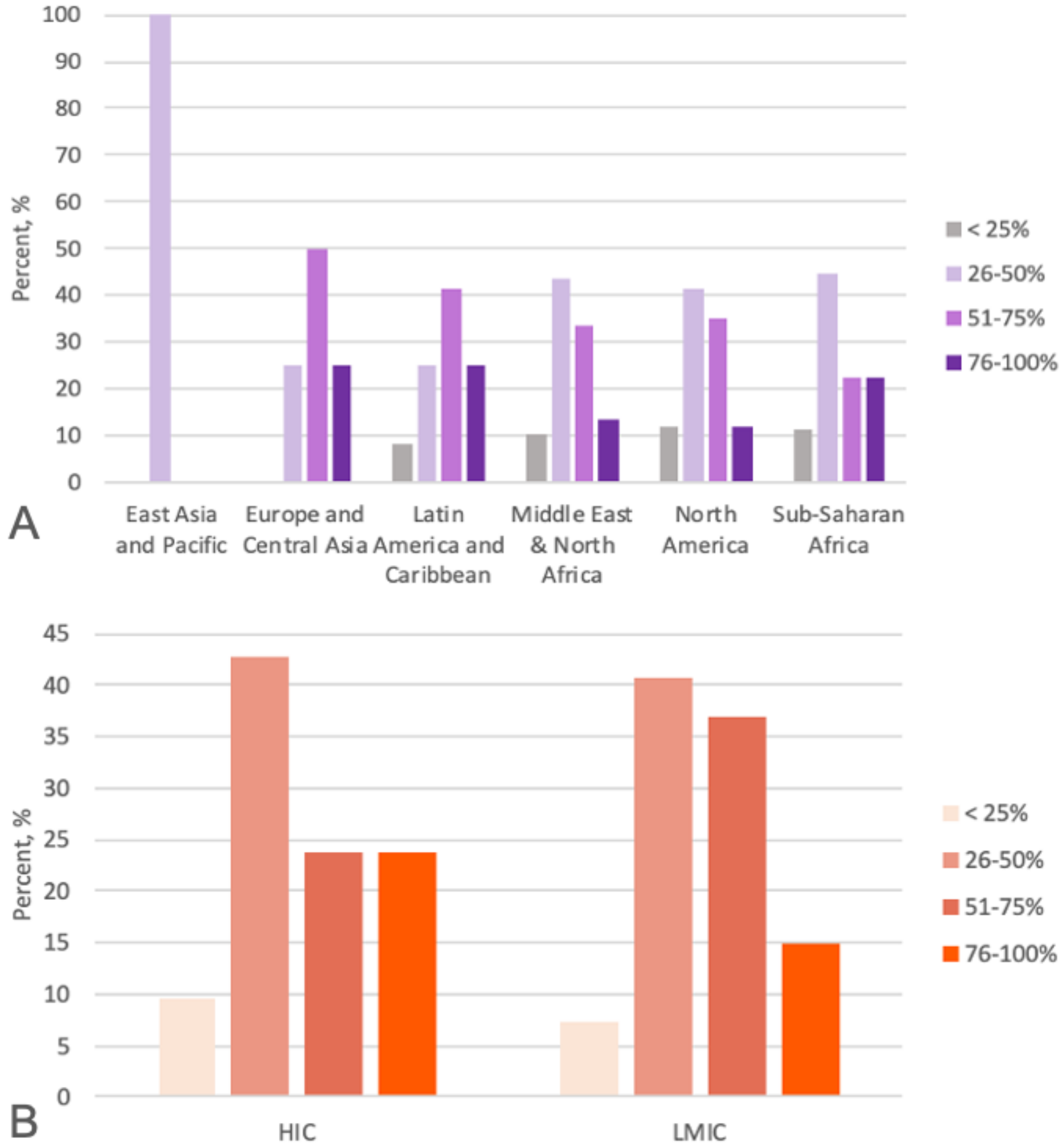

\section{Figure 3}

In your home country, what percentage of medical professionals are women? A. By Volunteer Home Region: B. By Volunteer Home Country Income Level: 


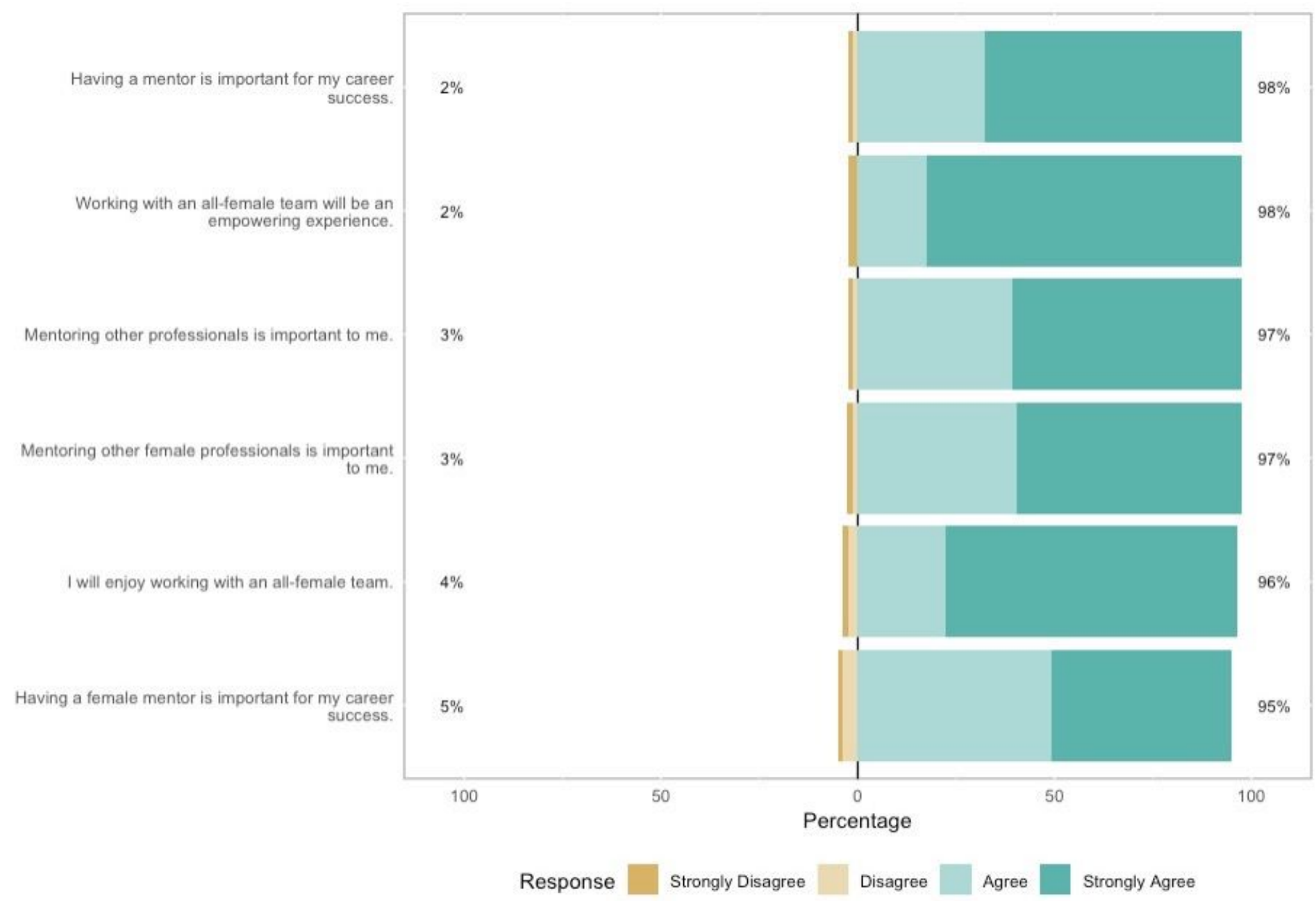

Figure 4

Opinions on mentorship before the mission 


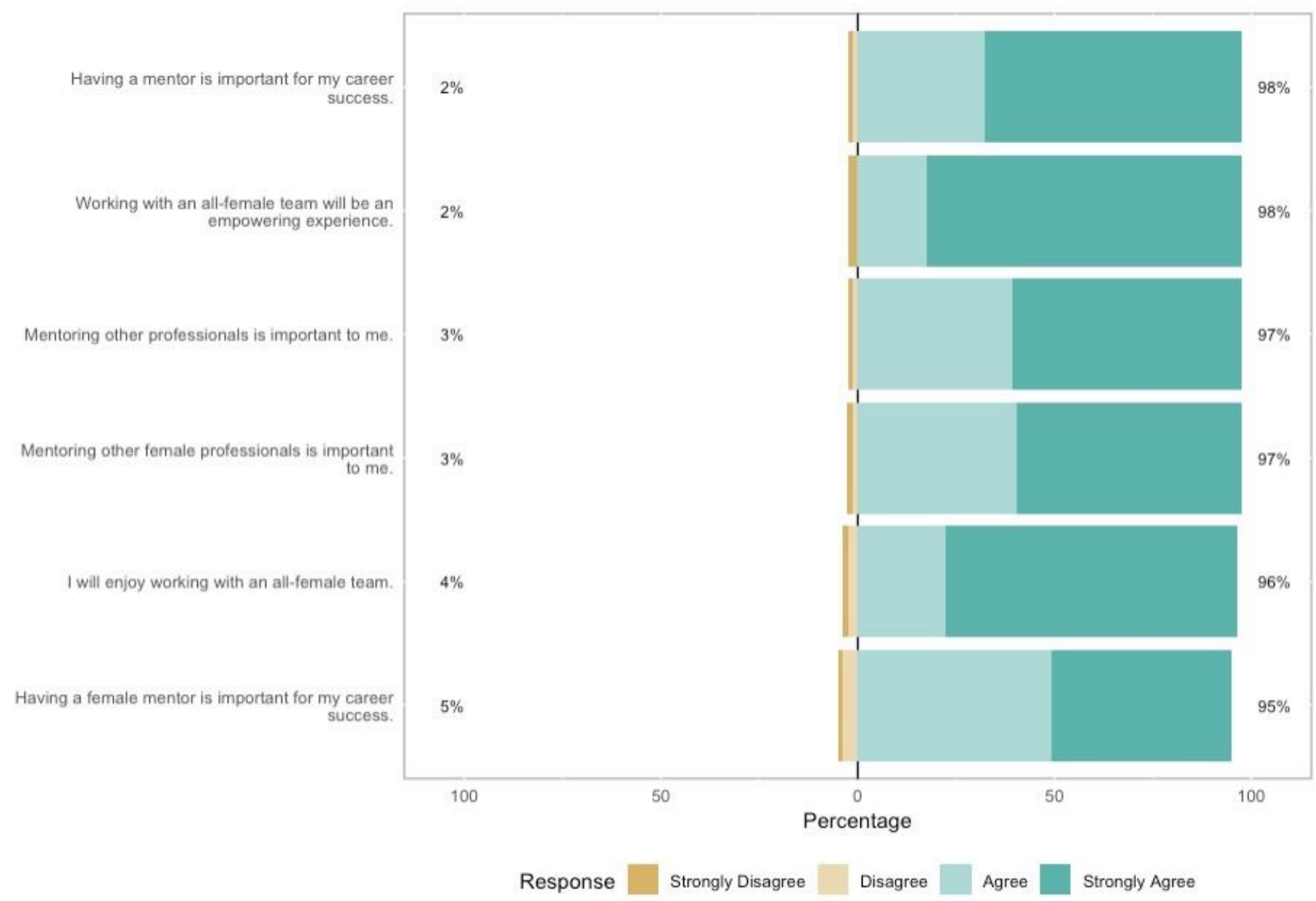

Figure 4

Opinions on mentorship before the mission 
Encouraged me to mentor other female professionals in my home country.

Helped me to establish professional contacts that I will maintain in the future.

Helped me to identify new mentors.

Motivated me to advance my professional career in my home country.

Given me more confidence in my ability to perform my job.

Inspired me to pursue leadership positions in my home country.

Increased my desire to be a team leader or educator with Operation Smile.
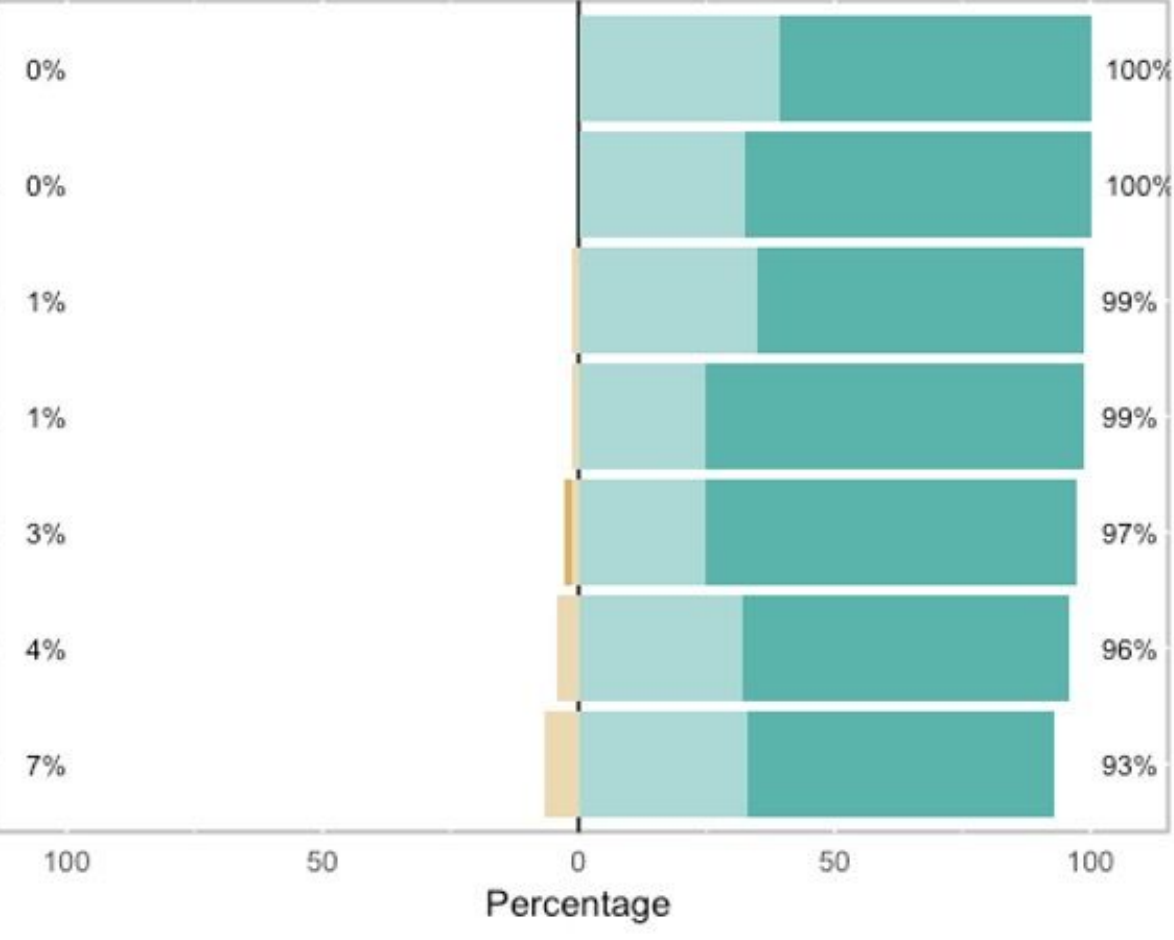

Response Strongly Disagree

Agree

Strongly Agree

\section{Figure 5}

\section{Opinions on mentorship and leadership after the Women's Mission}

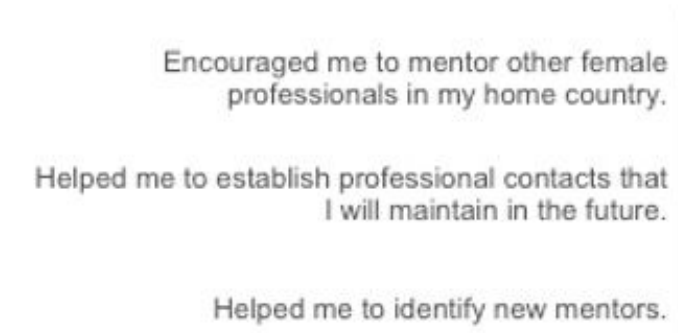

Motivated me to advance my professional career in my home country.

Given me more confidence in my ability to perform my job.

Inspired me to pursue leadership positions in my home country.

Increased my desire to be a team leader or educator with Operation Smile.

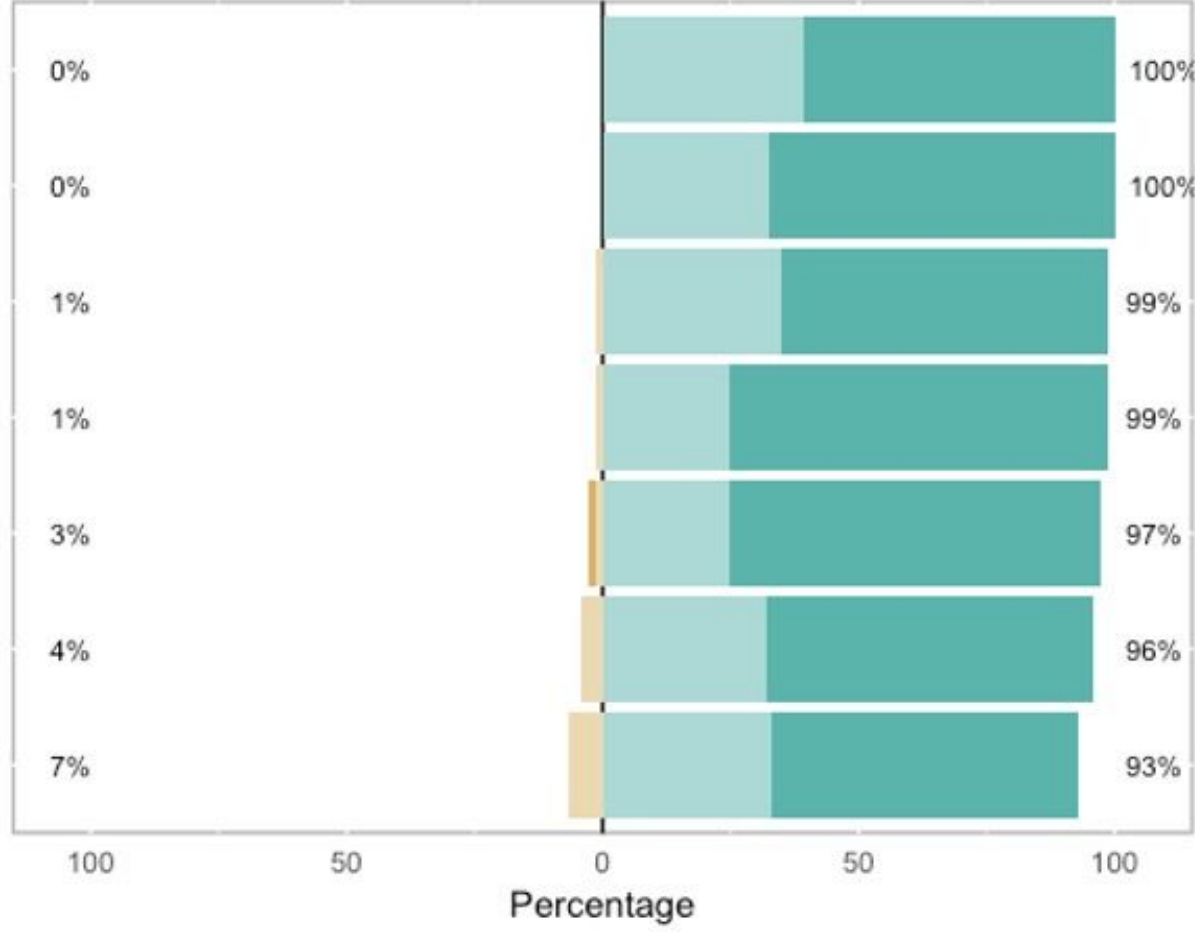

\begin{tabular}{l|l|l|l|l|l|l|l|l|l|} 
Response & Strongly Disagree & Disagree & Agree & Strongly Agree
\end{tabular} 
Figure 5

Opinions on mentorship and leadership after the Women's Mission

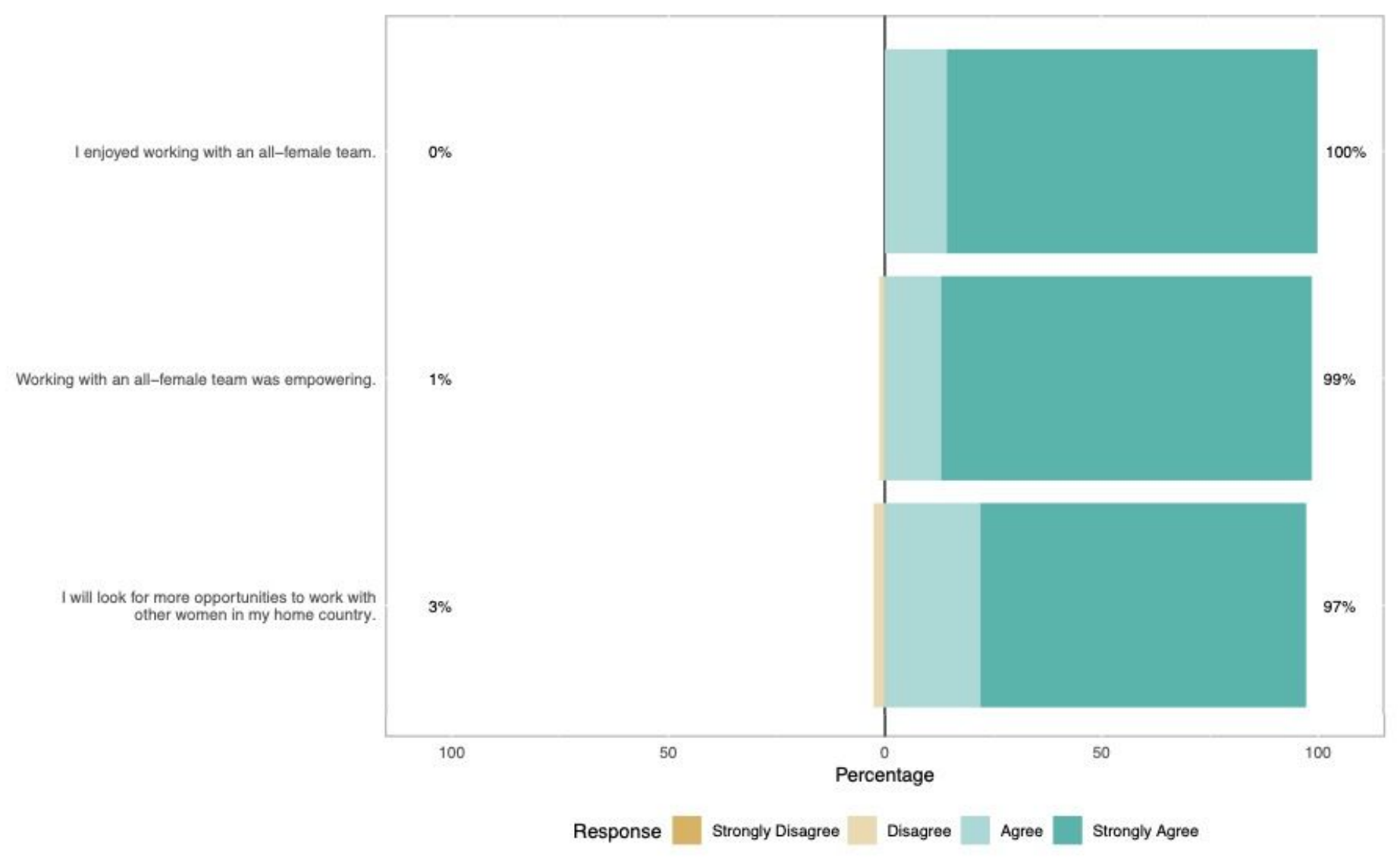

Figure 6

Opinions on working with other women after the Women's Mission 


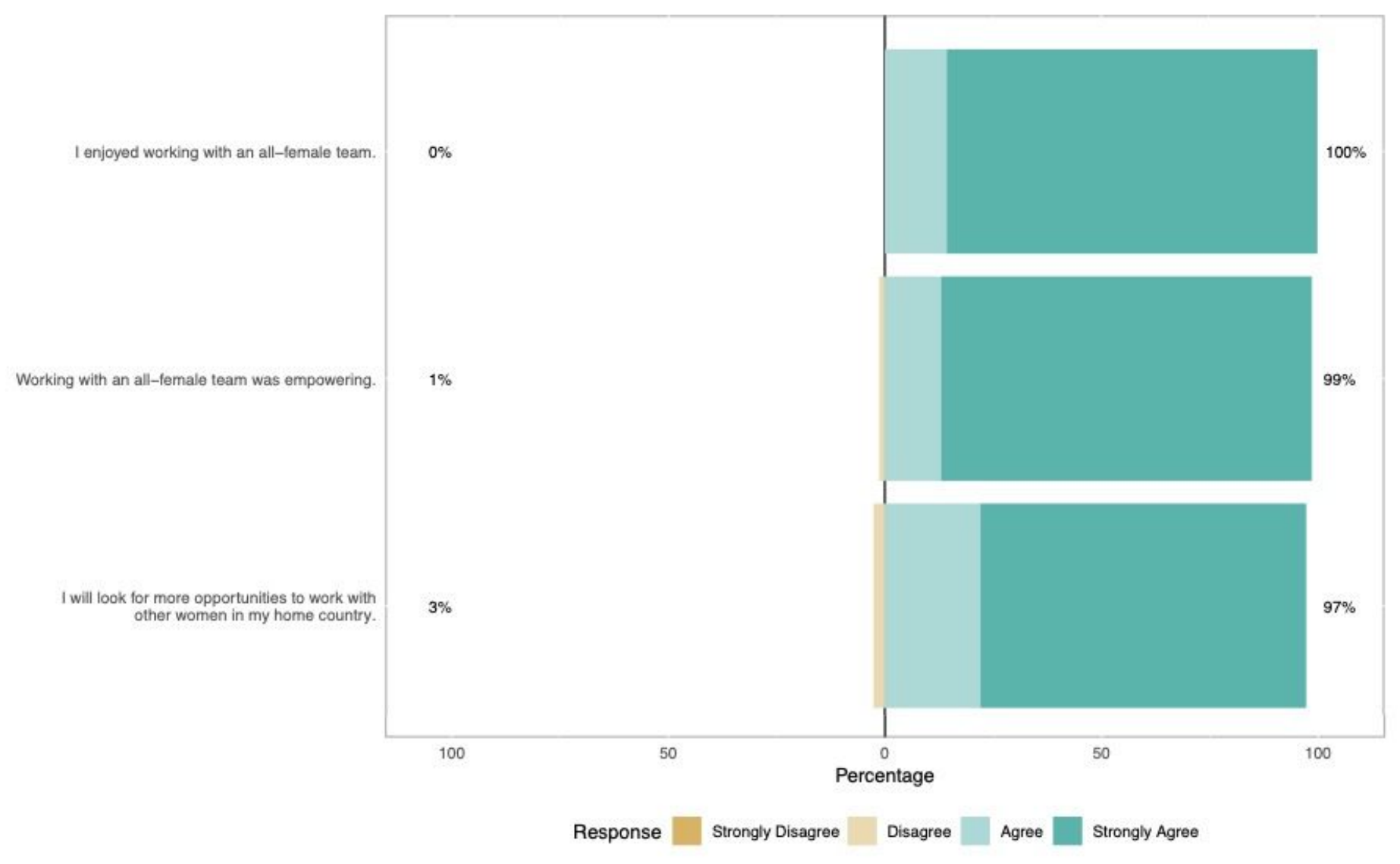

Figure 6

Opinions on working with other women after the Women's Mission 